\title{
Hearing Protection Success: Musicians Have a Favorable Response to Hearing Protection and Listeners Are Unable to Identify Music Produced by Musicians Wearing Hearing Protection
}

\author{
Nancy L. Nelson, AuD ${ }^{1}$ Mead C. Killion, $\mathrm{PhD}^{2} \quad$ Jennifer J. Lentz, $\mathrm{PhD}^{1} \quad$ Gary R. Kidd, $\mathrm{PhD}^{1}$ \\ ${ }^{1}$ Indiana University Department of Speech, Language and Hearing \\ Sciences, Bloomington, Indiana \\ Address for correspondence Nancy L. Nelson, AuD, \\ ${ }^{2}$ Etymotic Research, Inc., Elk Grove Village, Illinois \\ nelsonnl@indiana.edu \\ J Am Acad Audiol 2020;31:763-770.
}

\begin{abstract}
Keywords

- noise-induced hearing loss

- hearing protection

- musicians

Background Musicians are known to be at risk for developing hearing sensitivity and hearing-related problems given their occupational exposure to high-level sound. Among options for hearing conservation, earplugs are an effective and inexpensive choice. Adoption rates for musicians' earplugs remains consistently low, however, given concerns about the impact of hearing protection on their own performance as well as concerns that the resultant music will be a negative experience for listeners. In fact, few studies have (1) examined musicians' attitudes about using hearing protection while performing themselves and (2) determined whether music played by musicians wearing hearing protection sounds different to listeners.

Purpose The purposes of this study were (1) to evaluate how wearing musicians' earplugs affected musicians' perception of their performance while they were playing, and (2) to examine whether listeners can distinguish a difference between music recorded by musicians playing with and without earplugs.

Research Design Experiment 1: student musicians were recorded playing under two conditions (with and without wearing earplugs) and then were surveyed about their experience. Experiment 2: musically experienced and naïve listeners were presented with musical samples played by musicians with and without earplugs in an ABX format. Listeners responded by indicating whether the third stimulus $(X)$ was conditionally identical to the first (A) or second stimulus (B).

Results Experiment 1: while performing, musicians always preferred the no earplugs condition. The majority, however, rated the overall experience of playing with earplugs as generally positive. Experiment 2: listeners were unable to hear a difference between the two recordings.

Discussion In this experiment, musicians rated their experience playing without hearing protection more favorably than their experience playing with hearing protection, but most musicians rated their experience with hearing protection as generally positive. The inability of listeners to distinguish a difference in music played with and
\end{abstract}

received

November 5, 2019

accepted after revision

April 17, 2020
(C) 2021. American Academy of

Audiology. All rights reserved. Thieme Medical Publishers, Inc., 333 Seventh Avenue, 18th Floor, New York, NY 10001, USA
DOI https://doi.org/ 10.1055/s-0040-1719128. ISSN 1050-0545. 
without hearing protection suggests that the listening experience may not be adversely impacted by hearing protection worn by the performers.

Conclusion Earplugs are an inexpensive, noninvasive strategy for hearing conservation for musicians, and this study indicates that barriers to wearing hearing protection might be less problematic than previously reported.

Musicians present a unique challenge for hearing conservation (HC) management as they can be motivated to protect their hearing, but typical solutions to excessive noise may not be practical. For musicians, having and maintaining excellent hearing is important to their vocation. ${ }^{1}$ Standard HC methods, (e.g., unfiltered earplugs, sound baffles, exposure time limits), however, may not be feasible in the practice or performance setting. Sound exposure is also typically variable depending on the instrument, musical style, and location (size of practice/performance space and position relative to other musicians). Given these varying parameters, noise exposure may not trigger enrollment in Occupational Safety and Health Administration regulated HC programs (HCPs), ${ }^{2}$ and often musicians are reliant on their own willingness to comply with HC strategies. Previous studies have shown that compliance with one obvious solution-hearing protection (HP)-is typically low, although the negative impact of music on hearing has been demonstrated repeatedly and musicians almost universally report concern about some aspect of their hearing. ${ }^{3}$

Ensemble musicians may be at risk for noise-induced hearing loss (NIHL) generated by their own or other instrument(s). ${ }^{4}$ Hearing loss in musicians is well documented, even for younger practitioners, (e.g., college student musicians). Jansen et $\mathrm{al}^{5}$ found that a group of symphony musicians had more hearing loss than would have been predicted by age and gender. Phillips et $\mathrm{al}^{6}$ studied 329 student musicians (18-25 years) and found a $45 \%$ overall prevalence of NIHL, with the majority (78\%) having poorest hearing at $6,000 \mathrm{~Hz}$ (notch pattern on audiogram). Hearing loss caused by exposure to noise, however, can be a confusing symptom to the individual and those who are monitoring hearing sensitivity. It is well known that noise can result in temporary threshold shifts that ultimately return to previous sensitivity levels. Jin et $\mathrm{al}^{7}$ found this trend in college musicians playing in a marching band; initial test results indicated some NIHL; however, when these same musicians were tested again, the pure tone hearing loss was not permanent. Importantly, even when permanent hearing loss is not documented, animal research suggests that noise exposure can have a devastating impact on the hearing mechanism.

Potential long-term cochlear and neural changes caused by noise exposure have been demonstrated in animal models but to date, this phenomenon has not been well demonstrated in humans. Kujawa and Liberman ${ }^{8}$ studied the impact on noise in mice and uncovered powerful and convincing evidence that noise can cause cochlear and neural changes that may not be reflected in audiometric testing; in particular, measurable physiologic changes were present when puretone sensitivity was found to have returned to normal.
Kujawa and Liberman ${ }^{8}$ suggest that these cochlear and neural changes may be associated with problems such as tinnitus, hyperacusis, and difficulty hearing in background noise. In addition to hearing loss, Jansen et $\mathrm{al}^{5}$ found a preponderance of associated complaints of tinnitus, hyperacusis, and diplacusis.

College-age student musicians are typically at an age where intervention and adoption of HC strategies might be employed to prevent the development of permanent hearing loss and other related hearing problems before they begin. Some of the components of a model HCP for musicians are as follows: education, noise exposure monitoring, data collection, HP designed for musicians, hearing evaluation, limiting practice/performance times, acoustical baffles/dampers, and rostering/seat rotation. ${ }^{9}$ Among these options, HPs present an appealing strategy to $\mathrm{HC}$ as they are inexpensive, portable and noninvasive. Cook-Cunningham ${ }^{10}$ points out that while other HC efforts may or may not be consistently applied, the use of HP is in the control of the musician. It is encouraging that college-aged musicians and nonmusicians responded favorably to HP while listening to recorded music. ${ }^{11}$ Even so, musicians are typically reluctant to wear HP while they are playing. Reports on acceptance are varied but discouraging, with estimates of consistent HP adoption range from 6 to $20 \% .^{3}$

Chesky et al ${ }^{11}$ queried college student musicians about HP and found that they were receptive to wearing HP when listening to loud music, but were less enthusiastic about wearing HP when they were playing themselves. This resistance was rooted in multiple concerns: (1) negative impact on their own performance, (2) difficulty hearing others, (3) comfort issues, (4) insertion issues, and (5) communication problems. Similarly, Huttunen et $\mathrm{al}^{12}$ reported that symphony musicians believed that HP affected music timbre or dynamics or both. Given these concerns, the purpose of this study was to focus on the question of musicians' perception of music while wearing HP and listener's perception of the music produced by musicians wearing HP.

The emphasis in the literature has been on studying how musicians' perception of music is affected by wearing HP. Several studies have examined problematic aspects of using HP because of the occlusion effect as well as a negative impact on dynamic range, timbre, intonation, and balance. $^{9,13,14}$ Other studies have focused on the amount of attenuation or the frequency response of the attenuation provided by musicians' earplugs. These efforts to better understand the impact of HP on the musician are important but do not provide information regarding qualitative questions which were posed in the current project: (1) What is the relative impact of using HP on the musicians' perception 
of their own performance? and (2) Does music created by musicians using HP impact a listener's perception of musical quality?

\section{Methods-Experiment 1}

\section{Subjects}

Subjects were recruited from the Indiana University (IU) Jacobs School of Music student population. All members of an orchestral ensemble, scheduled for a recording session, were invited to participate and could self-select exclusion; one member was absent on the day of the recording leaving 36 participants. Institutional review board (IRB)-approved consent was obtained prior to inclusion.

The ensemble consisted of 12 female and 24 male graduate and undergraduate students of 18 to 31 years of age (average age: 22.5 years). The following instruments were represented: violin (11), viola (4), percussion (2), French horn (2), bassoon (2), oboe (2), flute/piccolo (1), flute (1), trumpet (2), clarinet (1), cello (4), bass (1), double bass (1), harp (1), and trombone (1). The range of experience with music was significant with participants reporting 7 to 20 years of playing experience (average of 12 years).

Twenty nine subjects consented to a pure-tone air conduction hearing test. Of these, all subjects had hearing $\leq$ $20 \mathrm{~dB}$ HL from 250 to $8,000 \mathrm{~Hz}$ except one subject who had moderately severe/severe unilateral loss (6,000 and $8,000 \mathrm{~Hz}$ ) and another subject with a unilateral threshold at $25 \mathrm{~dB} \mathrm{HL}(250 \mathrm{~Hz})$.

\section{Earmold Impressions and Earmold Use}

Participants were offered the option of having custom earmolds made or using noncustom earplugs from Etymotic Research, ER-20 ETY Plugs, for the recording session. ER-20 ETY Plugs provide approximately $20 \mathrm{~dB}$ attenuation between 125 and $8,000 \mathrm{~Hz}$. For those subjects selecting custom protection, earmold impressions were obtained using deep block insertion and a bite block to minimize occlusion effect and to optimize the fit, respectively. Musicians' earplugs were ordered from Westone Laboratories (standard 49 style with $15 \mathrm{~dB}$ Etymotic filters). Students were encouraged to use their earplugs during rehearsals 1 to 3 hours per day for the 7- to 14-day period prior to the recording session. All of the subjects used HP during the required parts of the recording session: 28 wore custom HP; 7 wore ETY-Plugs preformed HP, and 1 student wore his own noncustom HP.

\section{Recording}

All subjects were recorded playing the first two movements (Overture and Balcony Scene) of David Diamond's Romeo and Juliet $^{15}$ twice while wearing HP and twice while not wearing HP. The recordings were made with a stereo pair of microphones 6 " behind the conductor's podium and approximately 8 to $10^{\prime}$ high. The recordings were alternated between the without/with HP conditions (i.e., the first and third recordings: performed without HP; the second and fourth recordings: performed with HP). The duration of the recordings was about 4 minutes for the Overture movement and about
5 minutes for the Balcony Scene movement. The duration of the full recording session was 38:41.The music was recorded at 16-bit depth and a sample rate of $44.1 \mathrm{kHz}$.

Immediately following the recording session, subjects were given a questionnaire to obtain information about their musical background, use of HP history, and specific feedback about their experience playing music with and without HP. Questions included: how long they had been playing in elementary, junior high, high school, and college ensembles, whether they used HP for musical or nonmusical activities, if playing music had ever resulted in an episode of tinnitus and their school grade level. In addition, they completed a 12item survey about the impact of using HP while playing. The questionnaire was adapted from a choral study questionnaire with similar questions ${ }^{10,16}$ included in - Appendix A. Subjects used a 5-point bidirectional Likert scale (1: poor, 2: fair, 3: good, 4: very good, and 5: excellent) to rate their perceptions.

\section{Methods-Experiment 2}

\section{Subjects}

Subjects were recruited from the IU student population and Bloomington area. Ten subjects were enrolled in the IU Jacobs School of Music (experienced listeners) and 10 subjects had limited musical training (naïve listeners). Inclusion was based on hearing sensitivity and IRB-approved consent was obtained prior to inclusion. All participants had hearing thresholds within normal limits ( $\leq 20 \mathrm{~dB}$ HL for the frequencies 250 to $8,000 \mathrm{~Hz}$ in both ears, except one subject who had a unilateral threshold of $25 \mathrm{~dB} \mathrm{HL}(3,000 \mathrm{~Hz})$. Naïve listeners were seven females and three males ranging in age from 22 to 33 years (average: 26.5 years). Experienced listeners were five females and five males ranging in age from 19 to 30 years (average: 23.6 years). Subjects were paid $\$ 20.00$.

\section{Stimuli}

Music samples were 22 seconds in duration and randomly extracted from both movements of the recordings for both conditions (with and without HP). Ten samples were extracted from each of the recordings (e.g., movement 1: HP and no HP; movement 2: HP and no HP) using the same start location for each of the sound samples. Each of the samples was then shortened to 20 seconds using a randomly selected start time. This process was completed to avoid the possibility that the same start from two different samples would provide a confounding perceptual artifact that might cue the listener. Each of these samples was windowed using a 50 milliseconds rise/fall time. All samples were scaled to the same root mean square ( $\mathrm{rms}$ ) pressure and calibrated to $69.5 \mathrm{~dB}$ SPL. Scaling the samples to the same rms pressure may have removed overall level cues that were present in the raw samples.

Twenty samples were presented, 10 from the first movement and 10 from the second movement. The samples were presented in a randomized order using an $A B X$ format. In an $\mathrm{ABX}$ format, the third stimulus is conditionally identical to either the first or second stimulus. The interstimulus interval 
between samples was 2 seconds. The duration between tokens was 5 seconds and subjects were instructed that they could request more time if needed. Three musical samples are provided here (-Audios 1-3, online only).

\section{Audios 1-3}

Online content including audio sequences available at: Audio 1

https://www.thieme-connect.com/products/ejournals/ html/10.1055/s-0040-1719128.

Audio 2

https://www.thieme-connect.com/products/ejournals/ html/10.1055/s-0040-1719128.

Audio 3

https://www.thieme-connect.com/products/ejournals/ html/10.1055/s-0040-1719128.

\section{Procedure}

Pure-tone air conduction testing was completed at the beginning of the test session. All subjects completed a short survey about their exposure to musical training prior to testing.

Testing was conducted in a double-walled IAC acoustic soundbooth. Stimuli were routed through a Grason Stadler 61 diagnostic audiometer (manufactured by Grason Stadler) using a CD player (Model CDP-CD375 manufactured by Sony) via an external input and were calibrated using a recorded $1,000 \mathrm{~Hz}$ tone prior to each test session. Stimuli were presented at $69.5 \mathrm{~dB}$ SPL through a loudspeaker at 0 degree azimuth. Subjects were instructed to identify if sample $X$ matched sample A or sample B and record their responses on a printed score sheet. Subjects were instructed to record an answer for each token even if they were unsure of their answer.

\section{Recording Session and Musician Perceptual Survey}

The recorded peak levels for the music were essentially the same whether the musicians were wearing HP or not. The peak level in the first movement was $105.8 \mathrm{~dB}$ SPL with HP and $104.8 \mathrm{~dB}$ SPL without HP.

\section{Results-Experiment 1}

Results are summarized in - Fig. 1. A paired-samples $t$-test was conducted to determine if there were any differences in perception between those musicians wearing over-thecounter HP and those wearing custom HP. Similarly a paired-samples $t$-test was conducted to determine if there were differences in perception between those that had practiced with HP before the recording session and those who did not practice with HP before the recording session. Results of the $t$-tests showed that there were no differences between the groups except that the custom subjects with practice judged the custom earplugs to be more comfortable than the noncustom without practice. As such, groups were collapsed for descriptive results.

For every item, the without HP condition resulted in higher ratings than the with HP condition. Better than $90 \%$ of participants described their clarity of self, clarity of orchestra, pitch perception, and playing ability as good or better without HP. Importantly, however, the experience with HEP was judged to be good or better for a significant number of subjects (almost $70 \%$ or higher) for clarity of hearing self, clarity of hearing orchestra, pitch perception, and playing ability and comfort level. Even more significant was that $86.1 \%$ described their global experience (overall impression) playing with HP as good or better.

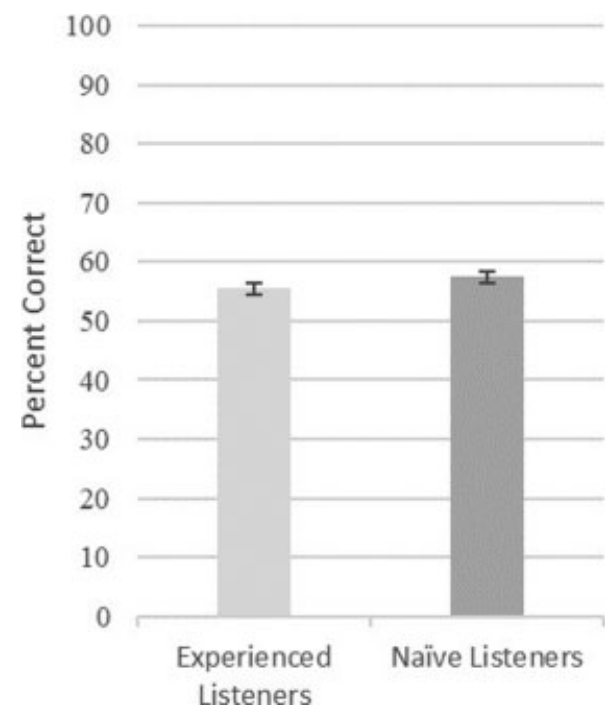

Fig. 2 Mean percent correct identification of music for HP and no HP conditions. Error bars represent standard deviation across 10 subjects. HP, hearing protection.
Fig. 1 Percentage of musician's responses of "good" or "better" to survey questions in percent.

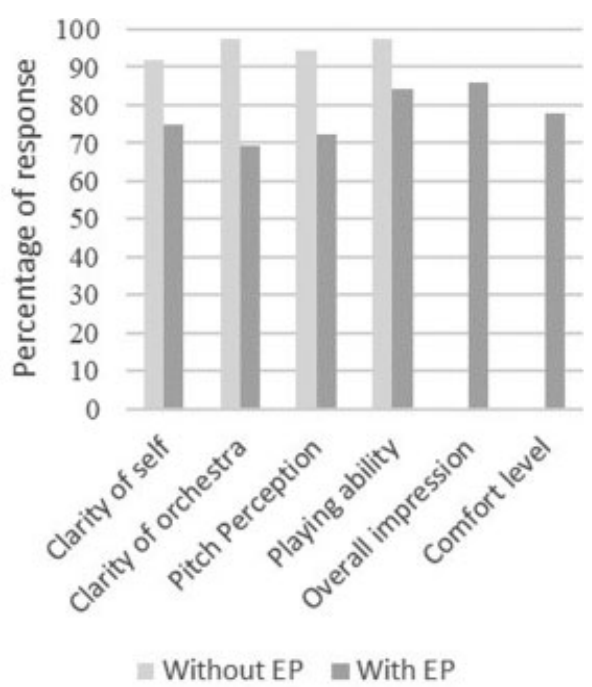

Journal of the American Academy of Audiology $\quad$ Vol. 31 No. 10/2020 $\quad$ @ 2021. American Academy of Audiology. All rights reserved. 


\section{Results-Experiment 2}

\section{Survey of Musical Training}

Experienced listeners were enrolled in the IU Jacobs School Music as music majors; musical training ranged from 5 to 10 years (average: 8.4 years). Naïve listeners were IU students or young adults not enrolled in the music school; musical training ranged from 0 to 9 years (average: 2.1 years, all precollege experiences). Listeners judged musical samples (described above) to determine if they could reliably identify music produced with and without earplugs.

-Fig. 2 illustrates scores for experiment 2. In this figure, the ability to correctly discriminate music produced by musicians wearing ear protection from music produced by musicians not wearing ear protection is graphed on a scale of 0 to $100 \%$ correct. The performance of experienced and naïve listeners is represented by separate bars. A paired-sample $t$ test was conducted to compare performance of the musically trained listeners and the nonmusically trained listeners. The results of the $t$-test revealed that the groups were not significantly different from each other $(t$-value $=-0.39$, $\operatorname{Pr}>|t| 0.6992)$. Note that $50 \%$ is chance performance; -Fig. 2 shows that performance for both groups was essentially at chance indicating that neither the experienced listeners nor the naïve listeners were able to tell a difference between music recorded with musicians wearing HP and with musicians who were not wearing HP.

\section{Discussion}

This study took aim at two problems that could be barriers to musicians using HP while performing themselves. First, musicians' own experience might be entirely negative. Second, musicians might be concerned that music produced while wearing earplugs creates a negative experience for listeners. The results of the study suggested that a majority of musicians (86.1\%) reported their overall impression of playing with HP as good, very good, or excellent. Importantly, naïve and experienced listeners performed at chance levels when asked to match musical samples that were produced by musicians wearing and not wearing HP. An important methodological element to this study was the timing of the comparison of both performing (immediately following the recording session) and listening to music played with and without HP (side-by-side comparisons). This immediacy created essentially an ecological momentary assessment; rather than relying on reports at a later time, perceptual judgments for both performers and listeners were made in real time.

College-age musicians appear to be quite aware of the negative impact of noise exposure. Chesky et $\mathrm{al}^{11}$ reported that $87.9 \%$ of his study population understood HP to be an effective HC strategy and 93.4\% felt that universities should supply HP to all music students. Even though the musicians in this study reported some previous exposure to HP, only one person in the ensemble reported that he would prefer to use his own earplugs for this project. Several of the students were excited to have an opportunity to be fitted with custom HP and as a group, they were uniformly aware of the dangers of being exposed to high-level music. Physical placement in an orchestra likely also drives motivation to wear HP. For example, those who are seated in front of the percussion or brass section are apt to be disproportionately impacted by ensemble noise. Notably, several musicians reported that they did not experience the music performed for this recording as loud (including the conductor), at least relative to other ensembles (jazz music was particularly mentioned as being much louder). The peak output (around $105 \mathrm{~dB}$ SPL), however, measured near the conductor's podium suggests a level that could be considered dangerous over a relatively short period ( 1 hour). College-age musicians are likely to experience high exposure levels for long periods from both practice and performance sessions and potentially from leisure activities as well.

Previous work has indicated that musicians seem to understand the value of using HP, but their compliance is exceptionally low; notably, at least one study reported higher compliance among musicians who were experiencing some type of hearing symptom as opposed to those who had no symptom. ${ }^{3}$ The results of this work supports the findings of Chesky et $\mathrm{al}^{11}$ who reported that college-age students (equal numbers of music and nonmusic majors) liked and valued noncustom HP for listening to music generally. Importantly, however, Chesky et al noted that musicians who wore HP while playing found their experience unpleasant. In particular, they reported difficulty hearing themselves and others in their ensembles as well as a decreased ability to communicate musically and to play music. Although O'Brien et $\mathrm{al}^{9}$ reported similar complaints, an encouraging finding in their data indicated significantly higher compliance for "occasional" use (55\%) than complete adoption "always" (7\%) among professional orchestral musicians using a combination of custom, noncustom, and electronic musicians' earplugs. O'Brien et al's work provides a platform for positive change. Given a chance to make an immediate comparison, musicians have a relatively favorable experience wearing HP while playing, maybe they would be persuaded to use HP with more consistency. One advantage the musicians in this study had is that they were asked to make a real-time analysis of playing with and without HP. Their own perception may have overruled any preconceived notions they held about what it would be like to play with HP. It is also possible that musicians could be encouraged to wear HP for exposures that are dangerously loud; even sporadic use of HP could be preventive if the correct time/dosing formula is known. There is an important reality in HC work that could be a trend in all types of occupations; expecting total compliance might not be a realistic goal, but encouraging and supporting musicians to employ HP and finding ways to support an upward trend in compliance are an important first step.

\section{Conclusion}

College student musicians reported their experience wearing custom and noncustom HP as generally positive and listeners were unable to hear differences in music that was played while musicians were wearing HP and without wearing HP. Together, these findings provide evidence in favor of 
HP use for musicians. Once musicians realize that their own experience may be altered, but still relatively positive and are reassured that their listeners will not be impacted, HP compliance may trend upward.

\section{Conflict of Interest}

Etymotic Research, Inc. provided ETY-20 earplugs and filters for custom made earplugs, as well as reimbursement for subject participants. Westone Laboratories, Inc. provided discount pricing on bulk earmold order for research purposes.

\section{References}

1 Hagerman B. Musicians' ability to judge the risk of acquiring noise induced hearing loss. Noise Health 2013;15(64):199-203

2 Department of Labor. Occupational Safety and Health Standards, (1981) Subpart G, Standard Number: 1910.95, Occupational Noise Exposure. Available at: https://www.osha.gov/laws-regs/regulations/ standardnumber/1910/1910.95. Accessed September 13, 2020

3 Laitinen $\mathrm{H}$. Factors affecting the use of hearing protectors among classical music players. Noise Health 2005;7(26):21-29

4 McBride D, Gill F, Proops D, Harrington M, Gardiner K, Attwell C. Noise and the classical musician. BMJ 1992;305(6868):1561-1563

5 Jansen EJ, Helleman HW, Dreschler WA, de Laat JA. Noise induced hearing loss and other hearing complaints among musicians of symphony orchestras. Int Arch Occup Environ Health 2009;82 (02):153-164

6 Phillips SL, Henrich VC, Mace ST. Prevalence of noise-induced hearing loss in student musicians. Int J Audiol 2010;49(04): 309-316
7 Jin S-H, Nelson PB, Schlauch RS, Carney E. Hearing conservation program for marching band members: a risk for noise-induced hearing loss? Am J Audiol 2013;22(01):26-39

8 Kujawa SG, Liberman MC. Adding insult to injury: cochlear nerve degeneration after "temporary" noise-induced hearing loss. J Neurosci 2009;29(45):14077-14085

9 O'Brien I, Driscoll T, Ackermann B. Description and evaluation of a hearing conservation program in use in a professional symphony orchestra. Ann Occup Hyg 2015;59(03):265-276

10 Cook-Cunningham SL. The effects of musician's earplugs on acoustic and perceptual measures of choral and solo sound. J Voice 2019;33(01):87-95

11 Chesky K, Pair M, Yoshimura E, Landford S. An evaluation of musician earplugs with college music students. Int J Audiol 2009; 48(09):661-670

12 Huttunen KH, Sivonen VP, Pöykkö VT. Symphony orchestra musicians' use of hearing protection and attenuation of custom-made hearing protectors as measured with two different real-ear attenuation at threshold methods. Noise Health 2011;13(51):176-188

13 Laitinen H, Poulsen T. Questionnaire investigation of musicians' use of hearing protectors, self reported hearing disorders, and their experience of their working environment. Int J Audiol 2008; 47(04):160-168

14 Helena Mendes M, Catalani Morata T, Mendes Marques J. Acceptance of hearing protection aids in members of an instrumental and voice music band. Rev Bras Otorrinolaringol (Engl Ed) 2007; 73(06):785-792

15 Diamond D. Romeo and Juliet, Overture and Balcony Scene. New York, NY: Boosey and Hawkes; 1944

16 Cook-Cunningham S. The Acclimatization Effects of Earplugs on Acoustic and Perceptual Measures of University Singers' Vocal Performances in Choral and Solo Settings. Doctoral Dissertation, University of KansasLawrence, Kansas2013 


\section{Appendix A}

Chamber Orchestra Participant Survey

Name:

Age: ___ Musical Instrument:

Number of years of musical lessons ___ Major

Number of years in Elementary band/orchestra

Number of years in Junior High band/orchestra

Number of year in High School band/orchestra Number of years in College band/orchestra

Please circle the year of school you are currently in:

Undergraduate: Freshman Sophomore Junior Senior

Graduate:___ Masters ___ Doctorate (Indicate which year of the program you are enrolled in)

Do you wear hearing protection? Yes or No (Circle one)

If yes, for which music activities?

If yes, for which nonmusic activities?

Do your ears ever ring after a practice or performance? Yes or No (circle one)

Please circle the number which best corresponds to your perception of your musical performance today:

1. My ability to clearly hear myself playing without the earplugs was:

\begin{tabular}{|l|l|l|l|l|}
\hline 1 & 2 & 3 & 4 & 5 \\
\hline Poor & Fair & Good & Very Good & Excellent \\
\hline
\end{tabular}

2. My ability to clearly hear myself playing with the earplugs was:

\begin{tabular}{|l|l|l|l|l|}
\hline 1 & 2 & 3 & 4 & 5 \\
\hline Poor & Fair & Good & Very Good & Excellent \\
\hline
\end{tabular}

3. My ability to clearly hear the rest of the orchestra when playing without the earplugs was:

\begin{tabular}{|l|l|l|l|l|}
\hline 1 & 2 & 3 & 4 & 5 \\
\hline Poor & Fair & Good & Very Good & Excellent \\
\hline
\end{tabular}

4. My ability to clearly hear the rest of the band/orchestra when playing with the earplugs was:

\begin{tabular}{|l|l|l|l|l|}
\hline 1 & 2 & 3 & 4 & 5 \\
\hline Poor & Fair & Good & Very Good & Excellent \\
\hline
\end{tabular}

5. My perception of the pitch without earplugs was:

\begin{tabular}{|l|l|l|l|l|}
\hline 1 & 2 & 3 & 4 & 5 \\
\hline Poor & Fair & Good & Very Good & Excellent \\
\hline
\end{tabular}

6. My perception of the pitch with earplugs was:

\begin{tabular}{|l|l|l|l|l|}
\hline 1 & 2 & 3 & 4 & 5 \\
\hline Poor & Fair & Good & Very Good & Excellent \\
\hline
\end{tabular}

7. My playing ability without earplugs was:

\begin{tabular}{|l|l|l|l|l|}
\hline 1 & 2 & 3 & 4 & 5 \\
\hline Poor & Fair & Good & Very Good & Excellent \\
\hline
\end{tabular}


770 Hearing Protection Success Nelson et al.

8. My playing ability with earplugs was:

\begin{tabular}{|l|l|l|l|l|}
\hline 1 & 2 & 3 & 4 & 5 \\
\hline Poor & Fair & Good & Very Good & Excellent \\
\hline
\end{tabular}

9. My ability to hear the conductor while not playing without the earplugs was:

\begin{tabular}{|l|l|l|l|l|}
\hline 1 & 2 & 3 & 4 & 5 \\
\hline Poor & Fair & Good & Very Good & Excellent \\
\hline
\end{tabular}

10. My ability to hear the conductor while not playing with the earplugs was:

\begin{tabular}{|l|l|l|l|l|}
\hline 1 & 2 & 3 & 4 & 5 \\
\hline Poor & Fair & Good & Very Good & Excellent \\
\hline
\end{tabular}

11. Rate your overall impression to playing with these earplugs.

\begin{tabular}{|l|l|l|l|l|}
\hline 1 & 2 & 3 & 4 & 5 \\
\hline Poor & Fair & Good & Very Good & Excellent \\
\hline
\end{tabular}

12. Please rate the comfort level of the earplugs:

\begin{tabular}{|l|l|l|l|l|}
\hline 1 & 2 & 3 & 4 & 5 \\
\hline Poor & Fair & Good & Very Good & Excellent \\
\hline
\end{tabular}

